Article

\title{
A Circular Economy for the Data Centre Industry: Using Design Methods to Address the Challenge of Whole System Sustainability in a Unique Industrial Sector
}

\author{
Deborah Andrews ${ }^{1, *(\mathbb{D}}$, Elizabeth J. Newton ${ }^{2}\left(\mathbb{D}\right.$, Naeem Adibi ${ }^{3}\left(\mathbb{D}\right.$, Julie Chenadec ${ }^{4}$ and Katrin Bienge ${ }^{5(\mathbb{C})}$ \\ 1 School of Engineering, London South Bank University, London SE1 0AA, UK \\ 2 School of Applied Sciences, London South Bank University, London SE1 0AA, UK; liz.newton@lsbu.ac.uk \\ 3 WeLOOP, 62750 Loos-En Gohelle, France; n.adibi@weloop.org \\ 4 Digital Infrastructure Association (SDIA), 20354 Hamburg, Germany; julie.chenadec@sdialliance.org \\ 5 Wuppertal Institute for Climate, Environment and Energy, 42103 Wuppertal, Germany; \\ katrin.bienge@wupperinst.org \\ * Correspondence: deborah.andrews@lsbu.ac.uk
}

\section{check for}

updates

Citation: Andrews, D.; Newton, E.J.; Adibi, N.; Chenadec, J.; Bienge, K. A Circular Economy for the Data Centre Industry: Using Design Methods to Address the Challenge of Whole System Sustainability in a Unique Industrial Sector. Sustainability 2021, 13, 6319. https://doi.org/10.3390/ su13116319

Academic Editor: Luis

Jesús Belmonte-Ureña

Received: 30 March 2021

Accepted: 26 May 2021

Published: 2 June 2021

Publisher's Note: MDPI stays neutral with regard to jurisdictional claims in published maps and institutional affiliations.

Copyright: (c) 2021 by the authors. Licensee MDPI, Basel, Switzerland. This article is an open access article distributed under the terms and conditions of the Creative Commons Attribution (CC BY) license (https:// creativecommons.org/licenses/by/ $4.0 /)$.

\begin{abstract}
The data centre industry (DCI) has grown from zero in the 1980 s, to enabling $60 \%$ of the global population to be connected in 2021 via 7.2 million data centres. The DCI is based on a linear economy and there is an urgent need to transform to a Circular Economy to establish a secure supply chain and ensure an economically stable and uninterrupted service, which is particularly difficult in an industry that is comprised of ten insular subsectors. This paper describes the CEDaCI project which was established to address the challenge in this unique sector; this ground-breaking project employs a whole systems approach, Design Thinking and the Double Diamond methods, which rely on people/stakeholder engagement throughout. The paper reviews and assesses the impact of these methods and project to date, using quantitative and qualitative research, via an online sectoral survey and interviews with nine data centre and IT industry experts. The results show that the project is creating positive impact and initiating change across the sector and that the innovative output (designs, business models, and a digital tool) will ensure that sectoral transformation continues; the project methods and structure will also serve as an exemplar for other sectors.
\end{abstract}

Keywords: circular economy; design methods; whole systems thinking; data centre industry

\section{Introduction}

Data centres are interior spaces that house electronic and electrical equipment that processes and stores digital data. The data centre industry (DCI) has evolved from zero in the 1980s into a global industry with 7.2 million sites [1] in 2021, annual electricity consumption is 200 TWh (i.e., $1 \%$ of global electricity consumption) [2,3] and carbon emissions are equivalent to those from the pre-Covid airline industry [4]; 60\% of the global population are now connected via smart phones, laptops, and other computing equipment [5], and the sector currently processes around 4.2 trillion gigabytes of data per year. It is predicted that the DCI will grow by around $500 \%$, by 2030 , as more people and objects are connected via the Internet of Things (IoT) [6]. Reliance on digital communications technology and, therefore, the DCI has developed to the point where any systems failure will adversely affect major commercial, health, education, and other sectors and dependence has been highlighted during the Covid pandemic when there was a notable increase in data traffic in response to remote working, education, and communication. The sector has helped to transform all aspects of life and has already proved very beneficial to many of those who have access to digital technology.

The speed and scale at which data centre technology, and equipment, developed far exceeded that of recycling infrastructure which, in conjunction with the fact that products were not designed with any consideration for treatment at end-of-life (i.e., linear design) 
and poor perception of second life products, means that the DCI is contributing to the increasing volume of e-waste that is generated every year. Critical Raw Materials are essential to DC and other electronic equipment and many are lost to landfill, and/or incineration, or cannot be accounted for at end-of-life. Consequently, unless there is a change in practice across all equipment life cycle stages, there is a threat to the supply chain for these and other materials, which will destabilise the market, the DCI, and all services that rely on it. Furthermore, current practice is environmentally and socially unsustainable.

There is an urgent need to transform the sector, but this is limited by various technical and behavioural barriers. The CEDaCI project is the first of its kind, and it was set up to instigate change and develop a Circular Economy for the Data Centre Industry by using a whole systems approach in a fragmented industry, comprised of 10 sub-sectors, that operate in individual silos. A whole systems approach is essential because decisions made, and actions taken, at each life cycle stage affect the sustainability of all other life cycle stages. Design thinking and design methods encourage holistic thinking, and, therefore, they were selected as models for CEDaCI; they underpin the structure and process to ensure that the project delivers what the sector needs. People/stakeholders and a 'hearts and minds' ethos are central to both methods; considering the history of and work practice across the DCI, however, there was a risk of failure if representatives did not engage with the various events and platforms. The project launched in October 2018, and in February 2021, a survey of DCI representatives was carried out to ascertain the extent to which the project structure and methods were working, to learn whether amendments or revisions were necessary to ensure success, and to assess the impact of the project to date.

This paper first describes the context of and barriers to a Circular Economy in more depth. It then describes the design methods and documents, the project structure, activities, and content, followed by details and results of a quantitative online survey and qualitative data gathered via semi-structured interviews. Participant numbers were limited to 44 (with 32 usable data sets) and 9 respectively. The response rate appears to be associated with the COVID-19 pandemic, which significantly increased data traffic, workloads and absence due to ill-health. The results were very positive and showed that the project methods and process were appropriate, although there were some shortcomings due to lack of representatives from two subsectors; the methods and process are raising awareness of the challenges and potential solutions in the DCI, and of circularity in general, as well as facilitating development of digital tools, business models, CE-fit designs and prototypes, and new recycling and CRM reclamation processes. Finally, these results endorse the project as an exemplar and the methodology could be adapted and applied in other industrial sectors facing similar challenges.

\section{Literature Review: Computing and Data Centres Past and Present}

\subsection{The Evolution and Expansion of Computing and Connectivity}

The history of computing is believed to have started around 2000 years ago with the Antikythera Mechanism, which was discovered in the sea near Greece in 1901; it is described as a mechanical computer that was used to make astronomical predictions [7]. Computing and calculation machines and methods were also developed in the China, India, and the Islamic worlds prior to, and during, the mediaeval period. It was not until the 1820s, however, that modern computing began in the UK when Charles Babbage developed his mechanical calculation machines-the Difference Engine and the Analytical Engine-with support from Ada Lovelace; she was the first person to recognise that a universal computer could do anything providing that it was given the right data and instructions, and, therefore, she is often referred to as 'the first programmer' [8]. Development continued slowly through the 19th and early 20th centuries with the introduction of electro-mechanical machines and, in 1937, there was a significant conceptual breakthrough when the British mathematician Alan Turing published a paper describing an imaginary machine that performed simple mathematical tasks by following precise logical steps [9]. He continued to develop this concept and machines throughout World War II and, with colleagues at 
GCHQ, achieved a significant technical breakthrough in 1942 when thermionic valves (generally used in telephone exchanges) were included in the machines. These components accelerated processing speed considerably and facilitated development of Colossus, the world's first completely programmable, electronic, digital computer, in 1943. Other notable parallel developments include the German Z series developed by Konrad Zuse (who used binary language to produce the first electronic calculator in 1938 and the first highlevel programming language 1943-1945) and ENIAC (Electronic Numerical Integrator and Computer), which was developed and launched, in the USA, in 1945 for military use. It is worth noting that neither the German or British governments recognised the importance of, nor funded, Turing or Zuse's research at the beginning of WWII and, consequently, the antecedents to and early Colossus computers were made from recycled components discarded by telephone exchanges for example. Nevertheless, the various technical and programming developments continued at pace after WWII, and numerous computers were developed for industrial, commercial, and military applications. Since then, computing technology has developed ever more rapidly; for example, keyboard input capability and transistor-based technologies were introduced in the late 1950s. As the evolution of mainframe computing continued, other developments enabled the introduction of personal computing. Examples include the invention of integrated circuits, silicon-based transistors in the late 1950s, the first single-person operated computer (1962), the first microprocessor (1973), the first Apple 1 and 2 computers (1977), the first IBM personal computer (1982), the first Apple Macintosh (1984), and the first portable computers in the early 1990s. The first computer game was developed in 1961 at MIT, after which various dedicated affordable computers were developed and sold from 1979; computer games were important because they helped to introduce the wider public to and popularise computers, which ensured their place outside the workplace and in the home $[10,11]$.

In 1965 Gordon Moore (an engineer and founder of Intel) predicted that, as density increased, the number of transistors that would fit on a computer chip would double every year-i.e., Moore's Law. Although this was amended to two years in 1975, this particular technical development, in conjunction with the development of new computer languages and software programmes, further accelerated the power and speed of computing; the development of data storage media, such as floppy discs and CDs, also increased functionality in the workplace and at home.

The earliest computers were stand-alone machines but gradually, research activity in the USA, France and UK facilitated the development of internal networks to which they were connected for data exchange. External networks were also developed and initially used in business and academia with the launch of a global Joint Academic Network (JANET) in 1984 to enable rapid information exchange and collaboration. During the 1980s, the British engineer and computer scientist Sir Tim Berners-Lee also developed a new digital information and communication language and network, which subsequently evolved to become the World Wide Web in 1989. Since then, the user group has expanded from 'geeks,' researchers, and academics to the general public, and in January 2021, over 4.66 billion people and $60 \%$ of the global population were 'connected' via the internet; of these individuals, $97 \%$ own a smart phone, $64 \%$ a laptop or desktop PC, and $34 \%$ a tablet [5].

\subsection{Data Centres}

While 'devices' (desk and laptop computers and mobile phones) serve as humandigital data interfaces, the hidden, but critical, enabler of connectivity is data centres (DCs). These facilities may be cupboard-sized or, (like the largest hyper-scale data centres in the world), equivalent in area to 93 football pitches; they all house digital data processing, networking and storage (ICT) equipment. Such is the popularity of the internet that, since its launch, the number of DCs around the world has grown considerably with estimated floor at 180 million $\mathrm{m}^{2} ; 10$ million $\mathrm{m}^{2}$ of which is in Europe, with $70 \%$ concentrated in North West Europe (NWE) [12]. 
There are three main types of centres: Enterprise (private facilities dedicated to supporting single organisations), Colocation data centres (where space, equipment, and/or data storage, and processing capability is rented to customers) and Cloud data centres (which are entirely owned and managed by companies who rent their virtual infrastructure to clients who run and manage their own applications and data). Cloud service providers include well-known brands such as Google, Facebook, Microsoft, and Amazon who have other business arms, as well as less publicly-known companies (e.g., Rackspace, OVHCloud, and Serverspace).

In 2015, there were over 8 million data centres around the world; this total has decreased to 7.2 million [1], although floor space and data traffic are continuing to rise, and by 2022 , there will be 4.2 trillion gigabytes of data processed per year. Development of the Internet of Things (IoT) will further increase data traffic and, consequently, it is estimated that data centre services will increase 300\% in Europe by 2025 and 500\% globally over 2018 figures [6].

Data centre equipment emits heat and, in addition to electricity for data processing and storage, DCs consume electricity for cooling and other operations. Consequently in 2018 the sector accounted for approximately 1\% (205 TWh) of global electricity use [2,3] and emitted as much $\mathrm{CO}_{2}$ as the commercial airline industry [4].

Since inception, the main concern and focus of the DC industry has been $100 \%$ uninterrupted service for customers. The most significant changes are increasing operational energy efficiency, some of which derives from changes in hardware, component design, and software; other reductions in electricity consumption have been achieved by changing from electro-mechanical air cooling to liquid cooling. This form of cooling can be system-based (e.g., open water circuits with adiabatic coolers or cooling towers) and/or localised (on-chip or submissive/immersion cooling). Examples of the latter use oil-based dielectric fluids whereas the former often use water; water is also used for humidification in air handling units. Water use is not a panacea and, although it can reduce operational energy inputs, it also has an adverse impact on the environment because the water discharged from data centres includes contaminants such as biocide chemicals (used to control Legionella in pipework and heat exchangers), dissolved salts (like limescale in kettles) and acidic or alkaline PH correctors, copper and steel corrosion protectors, and metal particles $[13,14]$ Water cooling also uses $0.2-0.8 \mathrm{~L}$ per $\mathrm{kWh}$ used [15] so the sector consumes the equivalent of 120,000 Olympic sized swimming pools per year, all of which contributes to global water stress. Another alternative to electro-mechanical air cooling is described as free cooling, which draws exterior air into the centre; in this case, cold air is beneficial and, consequently, a growing number of data centres, and hyperscale centres in particular, are located either near to or in the Arctic Circle. The combined use of these differing technologies means that the DCI has a significant impact on energy and resource consumption

In summary, computing and associated industries evolved very slowly until the late 1930s when there were some major conceptual developments. Development accelerated a little until the 1960s when it began to accelerate more rapidly in response to major technical innovations; development further accelerated in the 1970s and 1980s, and computers gradually became accepted in the domestic as well as academic and commercial environments. The World Wide Web was launched in 1989, and since then, the sector has expanded in scope, scale, and at speeds unlike any other sector in history; within 30 years, life for those with access to the computers and the internet (now $60 \%$ of the global population) has been transformed. Although many adverse impacts are associated with connectivity (e.g., cyber bullying and fake news) they are outweighed by the many diverse positive benefits. Examples include access to education in remote locations, micro-loans, and new business development among disadvantaged communities in Africa, video calls with friends and family, and on-line shopping during the COVID-19 pandemic. Industry is also benefitting from digital technologies, such as robotics, additive, and other new manufacturing techniques and quality monitoring all of which will grow concurrently with the IoT while information exchange has transformed logistics, transport, public, and private travel. 


\subsection{The Challenge of e-Waste}

The speed and scope of development, change, and the wish to provide consumers with smaller, lighter, more portable products with access to more data and storage capability, increasing processing speeds, product convergence, and functionality have all significantly influenced the design and manufacture of physical products. In the majority of cases, they have been and are designed for the present and life in use, which is generally limited by the design and life span of operating systems and firmware rather than failure of physical components.

The wish to both fulfil, and drive, consumer expectations has also driven developments in data centre equipment design. As previously mentioned, DCs may be repurposed spaces in commercial premises, but an increasing number are purpose built; size depends on location but generally, DCs have few windows. These centres are full of racks with servers, (which are, fundamentally, computers without screens), routers, switching and telecommunications equipment, mains and backup power supplies (such as batteries and generators, which are used to ensure uninterrupted service in the event of mains power failure), and cooling systems. The equipment is mainly comprised of metal and plastic cases and housing, and electrical and electronic components, the majority of which are made from a mixture of materials. Since the invention of integrated circuits, transistors and silicon chips, components have also decreased in size, but the underlying design principles of the equipment have not really changed.

This practice, in conjunction with rapid evolution of the sector, means that, in addition to other electrical and electronic products and sectors, the DC industry is contributing to the growing volume of e-waste/WEEE (waste electrical and electronic equipment) produced every year; in 2020 this was around 54 million tonnes (equivalent to $7.3 \mathrm{~kg}$ per person) and, unless there is a major change in culture, behaviour and treatment of equipment at end of life, this will increase to 120 million tonnes per year by 2050 [16]. This growth has been, and is being exacerbated, by the design and manufacture of products and components themselves, which makes separation of sub-components and materials either very difficult or impossible; although there is some evidence of steel, aluminium, and copper (i.e., larger components) recycling and gold recycling (which is found in relatively high concentrations in mobile phones and computers), the relatively low cost and size of the majority of individual components make recycling uneconomic unless executed at scale. It is impossible to say how much e-waste is actually recycled: while $17.4 \%$ is documented as collected and properly recycled, the remaining $82.6 \%$ cannot be accounted for; it is estimated that $8 \%$ is discarded in waste bins in high-income countries and that $7-20 \%$ is exported as second-hand products or e-waste to low-to-middle-income countries (LMICs) [16]. Although the exact whereabouts of the majority of e-waste is unknown, a considerable percentage is exported for processing and/or landfilling e.g., in Africa and China and similar countries, where practice and processes are frequently unregulated, often hazardous, and damage the environment and health.

Electrical and electronic equipment is complex and embodies approximately 69 elements: they include iron, aluminium and copper as well as precious metals (gold, silver, platinum, palladium, ruthenium, rhodium, iridium, and osmium), iron, aluminium, and copper as well as at least seven Critical Raw Materials (CRM). CRM are defined as such because they are economically and strategically important while availability is determined by concentration of production, geo-political location, potential of substitution, and current recycling rates. In 2011, the EU identified 14 such materials, but this increased to 20 in 2014, to 27 in 2017, and to 30 in 2020. They are already essential to renewable energy generation and low carbon technologies (such as wind turbines and batteries) and are becoming increasingly important to high technology products and emerging innovations $[17,18]$, and like more mundane electrical and electronic products, demand is increasing.

Unlike older and other technologies, products, and materials (e.g., furniture, vehicles, clothing, mechanical equipment, electrical equipment), which can be repaired and recycled at end of life with comparative ease. As stated above, electronics do not; furthermore, 
recycled and resource reclamation infrastructure remains limited; there is also evidence of ring-fencing reserves, and China is purchasing mines and land in Africa, for example [19] as well as limiting export of rare earth minerals [20]. The combined impact of these factors is a threat to and potential disruptor of the supply chain, which will affect manufacturing capability unless manufacturers have materials reserves.

\subsection{Data Centre Equipment Design and Manufacture}

Data centre equipment life varies according to type, and while some last for 20 years, the average life of other products such as servers ranges from under one year in hyperscale centres to $5+$ years in enterprise and colocation centres. Consequently, disruption to manufacture will influence current DC operators' ability to improve service (by upgrading equipment) or extend provision (by expanding current and/or equipping new data centres). Reliance on digital technology and services has grown to a point where interruption of many current services (e.g., health, traffic control) would have very adverse social and economic impacts; examples include increased costs which will eventually be passed on to end users and limit access to the internet by the poorest populations. Uncertainty about the supply chain will also affect longer term business and service planning.

The engineering profession is comprised of many specialisms (e.g., civil, mechanical, electrical and electronic, computing, aeronautical); the 'traditional' approach is monodisciplinary, and expertise and knowledge tends to be specific and deep but narrow, and, consequently, problem solving has not been holistic in that challenges have been addressed by developing fixes for individual problems and linear thinking, rather than going back to first principles and/or adopting a whole systems approach. This approach is prevalent in the data centre industry, which is comprised of 10 internal subsectors and 1 external subsector (see Figure 1), each of which employs highly talented and skilled professionals. However, there has been very little interaction between the subsectors and, consequently, problems solved in one part of the system (subsector) have often created problems in other parts of the system, one example of which is described above, i.e., that of reducing energy consumption by increasing water use.

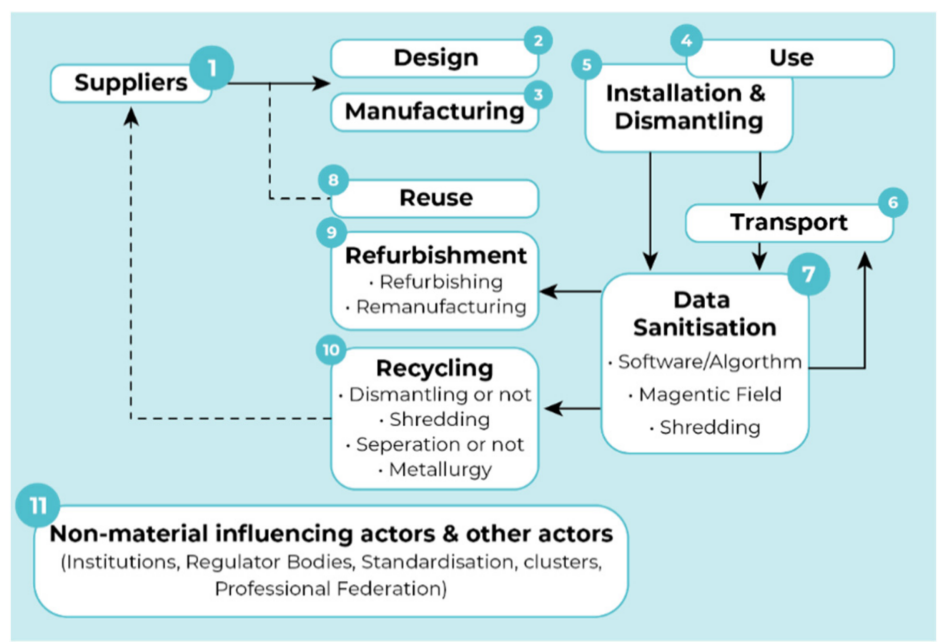

Figure 1. Data Centre Industry actors and sub-sectors, the CEDaCI project.

In summary, the data centre industry is unique: the rate and scale of growth of the technology and sector are unprecedented, as is the impact of services provided (specifically connectivity) on almost every aspect of daily life in the developed world, and influence is increasing in the developing world. To date, the sector has focused on the short term and provision of increasingly fast and extensive services, based on a linear take-makeuse-dispose economy. The fundamental design of data centre equipment has not changed since the sector began, and most disruption and innovation are associated with the services provided by the technology, rather than the technology itself. The above factors necessitate 
an urgent and systemic review and change in practice across the sector to ensure that future services remain uninterrupted and that the sector becomes environmentally, socially, and economically sustainable. This could be assured through development of a sectoral Circular Economy although silo working and fragmentation currently presents considerable technical and behavioural challenges to this [21]. Section 3 will discuss CEDaCI-a project that was developed to initiate a Circular Economy for the Data Centre Industry; the methods employed to underpin this project are also described, and then, their impact is investigated, and assessed, via the quantitative and qualitative data in Section 4.

\section{CEDaCI-A Circular Economy for the Data Centre Industry}

The particular and diverse challenges of the data centre industry are unique and require an innovative whole systems approach to instigate major change because decisions made and actions taken at each life cycle stage affect the sustainability of all other life cycle stages. The Circular Economy for the Data Centre Industry (CEDaCI) project was initiated to kick start this change; it was developed and executed by academics and consultants from several different disciplines (including product and engineering design, social and behavioural sciences, business and life cycle management, and materials science), with knowledge of, but working outside, the sector, which is helping them to overcome these challenges. The project includes around 20 partners based in North West Europe; it is led by London South Bank University and other main partners include Operational Intelligence (UK), WeLOOP, TND and TEAM2 (France), GreenIT Amsterdam and SDIA (Netherlands), and Wuppertal Institute for Climate Environment and Energy (Germany). The project structure is underpinned by respected and proven methods for innovation, namely Design Thinking and the Design Council's Double Diamond process. Both methods also support a whole systems approach, which is critical to the development of any circular economy, and in particular, that within fragmented sectors.

\subsection{Method: Design Thinking and the Double Diamond Framework}

Design Thinking has always been integral to design practice and the design profession but the approach was introduced to the business community in 2008 [22] and wider community in 2009 [23] by Tim Brown, who defines it as 'a human-centred approach to innovation that draws from the designer's toolkit to integrate the needs of people, the possibilities of technology and the requirements for business success' (see Figure 2); it is also defined as a hands-on, user-centric ideology [24], and a non-linear iterative process that teams use to understand users, challenge assumptions, redefine problems, and create innovative solutions [25], and it has evolved to become an established practice. It has already proved successful to many sectors because it addresses the biases and behaviours that hamper innovation [26]; its value is also recognised well-beyond the design profession, and a number of reputed leadership and training establishments now offer courses in Design Thinking, such as Cambridge University [27] and Massachusetts Institute of Technology, for example [28].

Prior to Brown's public dissemination of Design Thinking, in 2005 the UK Design Council published the Double Diamond, which has become a universally accepted depiction of the design process (see Figure 3). The developers also acknowledged that the process and methods were already integral to, and widely practiced by, the design profession but the diagram was devised to structure the process more clearly and, therefore, to both support designers to progress, from problem to solution, and to help them to explain the process to clients. The original version lists four stages, the first two of which (Discover and Define) encourage broad and deep exploration of the challenge (divergent thinking), while the second two (Develop and Deliver) encourage focused action (convergent thinking) [29]. 


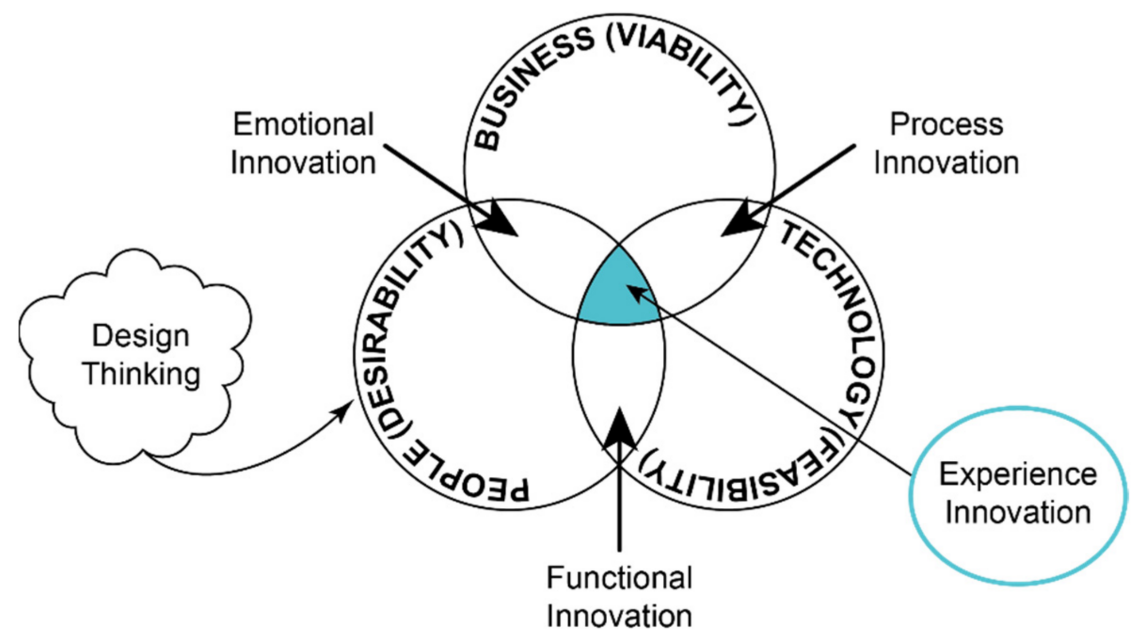

Figure 2. Design Thinking used to initiate innovation, adapted from IDEO.

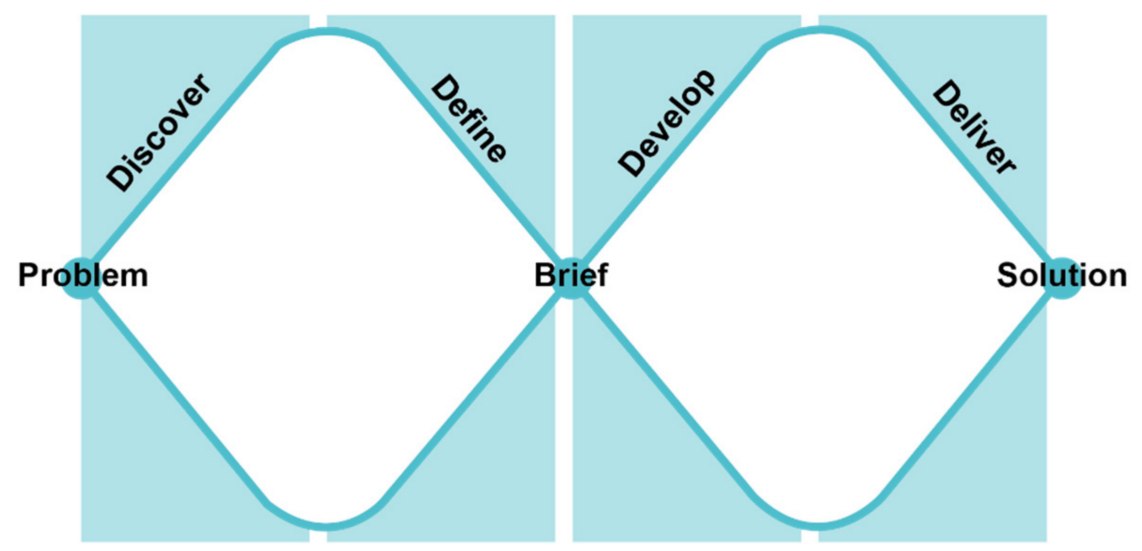

Figure 3. Adapted from Design Council Double Diamond, 2005.

The Double Diamond was also very successful within, and beyond, the design community, and in 2015, it was revised and enhanced to form a framework for innovation and to provide a structure for Design Thinking (see Figure 4). In Design Thinking and the Double Diamond framework, people (stakeholders) are critical to the process and successful project delivery. This is further clarified in the Double Diamond model, which includes stakeholders in all stages as follows. The entire process is underpinned by Engagement (building relationships between citizens, stakeholders, and partners) and Leadership (to create conditions to allow innovation, including culture change skills and mind sets). Design Principles and Methods were also added to the revised Double Diamond model and, again, both specify engagement strategies: Design Principles-1. be people centred; 2 . communicate visually and inclusively; 3 . collaborate and co-create and 4 . iterate, iterate, iterate-and Methods Bank-1. Exploration (of challenges, needs, and opportunities), 2. Shape (prototypes, insights and visions) and 3. Build (ideas, plans, and expertise) [30]. The principles and methods are integrated throughout the process, so stakeholders should be regularly consulted to ensure that the project output meets their current and future requirements. 


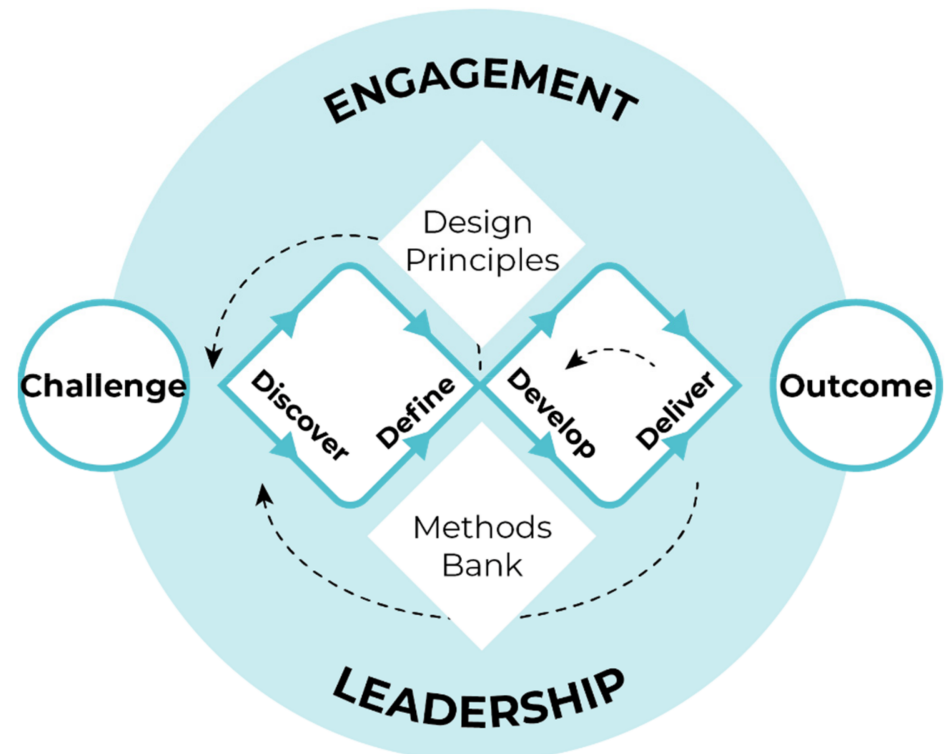

Figure 4. Adapted from Design Council Double Diamond framework for innovation, 2015.

\subsection{Stakeholder Engagement and the CEDaCI Project}

Stakeholder engagement has already proved beneficial to many sectors because it clarifies communication and the exchange of ideas and helps all parties to develop a thorough understanding of issues, alternative perspectives, and potential solutions; it also strengthens the resources of the involved individuals and groups by increasing awareness, confidence, skills, and co-operation, and it improves sustainability of the initiatives by increasing the quality of decisions and their acceptance among stakeholders [31]. The reasons for its success as a strategy are associated with motivation and fundamental human psychology: engagement has been defined as the sum of supportive conditions for authentic expression; it is motivated by either cognitive factors (such as a rational work goal), emotional factors (a state of mind that affects behaviour) [32], or motivated by a combination of cognition and emotions [33]. These drivers tend to vary according to role, so consumers are motivated by emotional factors such as empathy, gratitude, and trust [34] while stakeholders are motivated by more functional and rational (cognitive) factors [35], which may be evidenced as goal-directed behaviours such as accomplishing a predetermined purpose [36].

Stakeholder engagement was seen as critical to the CEDaCI project to enable and ensure a whole systems approach to the challenge, via knowledge exchange between the project team members and stakeholders and among stakeholders from the various sub-sectors. However, the history and evolution of and behaviours across the Data Centre Industry meant that there was a risk of non-engagement. The leadership team believed they could reduce this risk to a manageable level by stimulating interest through first- and second-hand contacts and by meeting potential participants in person at trade and other events, although this is a time and resource intensive activity.

The structure of the DCI means that members are often simultaneously stakeholders and consumers (i.e., they are involved in delivery and procurement and use of products and services) and therefore, they are motivated by both cognitive and emotional factors. In the context of $\mathrm{CEDaCI}$, for example, as stakeholders, their eventual goal is to increase sustainability of the DCI and build a Circular Economy; as consumers, they meet the team partners and colleagues from across the industry, and by sharing experience and knowledge, they develop empathy and trust.

In order to reach and engage as many actors as possible during and after the project three types of activity were developed and employed: 
- Working Groups (WGs): stakeholder-focussed meetings by invitation and referral where experts associated with the sector discuss and advise on general project activities to ensure they meet sectoral requirements; 20-25 participants per event

- Co-creation Workshops (CCWs): consumer and stakeholder focused events by invitation and referral where experts guide and review the design and development of specific outputs; $20-25$ participants per event

- A virtual pan-sectoral Network (NM): consumer and stakeholder focused platform with open membership to publicise project activities, progress, news and events, and encourage knowledge sharing and connection among members during and after the project (100 members to date)

\subsection{Project Structure and Process}

As stated above the four stage Double Diamond framework project underpinned the project structure and stakeholders were also involved throughout every stage.

- Discover - research and analysis of the entire DCI and associated activities; secondary data collected from publications and primary data through contact with stakeholders

- Define-Brief, project scope and key outputs were developed in response to the above findings by the core CEDACI team and confirmed in Working Group meetings (with partners and stakeholders)

- Develop - regular WG meetings and CCWs with stakeholders to identify their requirements and wishes, share knowledge, and gain feedback to support iteration and execution of the Project Pilots (A - design and manufacture; B-product life extension increased by incentivising secondary market; $\mathrm{C}$-new recycling processes and increased CRM reclamation) and digital tools.

- Deliver-Project output (e.g., bespoke Eco-design and CRM assessment tools; overall Data Centre sustainability assessment tool) tested and reviewed by stakeholders/consumers; tools and other output refined in response to feedback. Following final delivery CE training offered to 50+ SMEs (stakeholders/consumers).

The project and progress are continually publicised, via a dedicated website, and regularly promoted via panel discussions and presentations at global trade events (e.g., Data Centre World, Data Centre Dynamics), and specialist conferences (e.g., TechUK, Forum for Sustainability through Life Cycle Innovation) and via social media platforms to raise awareness, maintain a public profile, and engage with as many DCI and IT industry representatives as possible.

\section{Results}

The anecdotal response to invitations and attendance of the various meetings and events was positive; however, a more objective assessment of the level and impact of engagement and suggestions for improvement was sought in order validate the whole systems approach, the engagement strategy, and perceived impact of the project overall. Initially, quantitative data was collected via an online survey to produce a general overview of the response to the CEDaCI project and the level of stakeholder engagement. This was followed with a more comprehensive qualitative research using semi-structured interviews to gather deeper insights. (See Supplementary Materials for the list of questions).

\subsection{Quantitative Research}

The on-line survey of CEDaCI Network Members was published via the CEDaCI Network and comprised of 18 questions, most of which required multi-choice/tick box responses, but 3 also offered respondents the opportunity to add comments. Standard data collection and analysis software was used to set up and run the survey, which was live for 14 days. The response rate was fair $(44 / 100 \mathrm{NM})$ and once the data were cleaned there were 32 usable datasets; although a larger dataset would have been better, it was reasonable for this type of survey and deemed valid during a global pandemic. COVID-19 adversely affected many businesses and individuals (e.g., through illness, work-life balance, caring 
and educator roles, furlough, and redundancy); however, there was a marked increase in data traffic and associated activity and workloads in the data centre industry as populations worked, studied, and communicated remotely, which limited time for DCI members to engage in non-essential activities like surveys and interviews.

The respondents included actors from 8/11 life cycle stages/subsectors as shown in Figure 1 above. Most respondents work in companies with more than one main activity while others work in companies that engage in main and secondary activities, as shown in Table 1 below, which also showed that the main businesses of respondents vary, and 8 are directly involved in data centre systems design and operations ( 2 and 4$), 3$ in refurbishment and reuse (8 and 9), 1 in de-installation (5) and 1 in recycling (10); secondary business activities include systems design (2), data sanitisation (7), refurbishment, and reuse (8 and 9) and recycling (10).

Table 1. Respondents to CEDaCI engagement survey-identified by subsector-32 responses.

\begin{tabular}{lcc}
\hline Data Centre Industry Subsector & Main Business Activity & Secondary Business Activity \\
\hline 1. Suppliers & 0 & 0 \\
2. Design (DC systems) & 8 & 2 \\
3. Manufacturing & 8 & \\
4. Operation/use & 1 & \\
5. Installation and dismantling & & 7 \\
6. Transport & 3 & 10 \\
7. Data sanitisation & 3 & 10 \\
8. Reuse & 1 & 10 \\
9. Refurbishment & & \\
10. Recycling & & \\
11. Other actors e.g., & & \\
policy/regulation bodies & & \\
\hline
\end{tabular}

Respondents' roles are as follows: the majority (18/32) are employed as data centre design, strategy, management, and operations consultants, or as sustainability and circular economy leads for global and national private companies, public, and non-profit organisations, and all respondents (32) hold senior positions, such as managers, senior managers, CEOs, directors, and owners.

Table 2 below shows that all 32 respondents were Network members by default but analysis of the results showed that 9 were only Network members, 16 participate in the Network and either the Working Groups, or Co-creation Workshops, and 7 participate in the Network, Working Group, and Co-creation Workshops.

Table 2. Respondents to CEDaCI engagement survey-level and type of activity-32 responses.

\begin{tabular}{cc}
\hline Activity & Number of Respondents \\
\hline Network members & 32 \\
Network Members only & 9 \\
Network membership and Co-creation Workshops (CCW) & 16 \\
or Working Group (WG) membership & 7 \\
\hline Network membership and CCW and WG membership & \\
\hline
\end{tabular}

The respondents have been engaging throughout the project and 27/32 volunteered information about the date that they joined the Network: 11 as soon as it was launched in January 2019, a further 10 during 2019 and 6 in 2020 Network membership is open to anyone whereas participation in the Working Group and Co-creation workshops was by invitation only or referral to ensure that there were representatives from as many subsectors as possible and numbers were manageable. The WG and CCW invitations were circulated soon after the project launch and again most respondents (16/19) joined, and have participated regularly, since invited, and 3 have joined between September and 
December 2020 by referral, all of which indicates commitment to the project and activities (see Table 3).

Table 3. Respondents to CEDaCI engagement survey-length of membership-27 responses.

\begin{tabular}{cc}
\hline Joining Date-Network & Number of Respondents \\
\hline January 2019-launch & 11 \\
During 2019 & 10 \\
During 2020 & 6 \\
\hline Joining Date-CCW and WG & 16 \\
January 2019-Launch & 3 \\
September-December 2020 & \\
\hline
\end{tabular}

23 Network members also connect with the CEDaCI team outside the organised events (see Table 4) but connection appears to be local (e.g., Network members based in the UK connect with LSBU, those in France with WeLOOP, in the Netherlands with GreenIT Amsterdam/SDIA, and with those in Germany with Wuppertal Institute); this could be due to language or mutual contacts in the local area, for example. Levels of contact also vary and although 9 members have not yet made personal contact 11 members make intermittent contact, 3 once a month, 6 once since joining, but 1 person contacts the project team at least once a week. Most respondents selected more than one reason for joining the Network: only 8 joined to provide advice and 13 to connect with other members of the Network; the most popular reasons cited were to share information (with the project partners) (17) and to follow project progress (17). With regard to the benefits of Network membership, once again, some respondents selected one benefit, others 2, and others 3 . The main benefit was identified as being able to connect with colleagues in the same subsector (selected by 14 respondents), the second was to get information about data centre sustainability (9), and only 5 respondents saw connecting with other subsectors as beneficial; this is not entirely surprising and reflects the silo-working practice (see Table 4). As previously stated, silo working and attitude is common to the DCI, so the results were not entirely surprising and the project team realise they have to do more to engage cross-sectoral communication. Finally, 11 respondents follow CEDaCI on LinkedIn, 4 on Twitter, and 2 on both platforms, i.e., 18/32 respondents; this could be due to a low level of engagement with social media across the group or to ignorance about the CEDaCI accounts. The team will publicise the links more widely through other DCI accounts and work to increase Network membership and engagement.

Table 4. Respondents to CEDaCI engagement survey-reasons for joining and benefits: 23 responses.

\begin{tabular}{cc}
\hline Reason for Joining & Number of Respondents \\
\hline To provide advice & 8 \\
Connect with Network members & 13 \\
Share information with project partners & 17 \\
Follow project progress & 17 \\
Perceived Benefits & \\
Connecting with individuals in same subsector & 16 \\
Connecting with individuals in different subsectors & 5 \\
Get information about DC sustainability & 9 \\
\hline
\end{tabular}

In summary, the respondents were very positive about the project and their experience; their early enrolment, and regular participation in activities, reflects their on-going commitment to the project.

They are also informed about sustainability, and their senior positions and roles, within their organisations, indicate that they all have potential to influence practice either inside and/or outside their organisation. They see participation as beneficial for networking, although connections tend to be local and limited to their sub-sector rather than 
cross-sectoral. There was no negative feedback, but there were several suggestions about increasing project visibility and marketing drives to increase uptake, including demonstration and training sessions for the UK government Sustainable Technology Group, which positively endorses the project and its output. This feedback was useful, but very general, and so, a further study was undertaken to gain deeper insights into the strengths and weaknesses of the project and stakeholder engagement so far.

\subsection{Qualitative Research}

In order to gain deeper understanding of the response to the project, and to find out whether the methods employed were successful or needed to be adjusted or revised, a more extensive survey was also undertaken. As stated above, DCI representatives were affected by the pandemic and although 12 candidates responded to interview requests and were invited to participate in the research activity, two then said they were unable to do so due to a high volume of work and one candidate had to withdraw at the last minute for personal reasons, so there were 9 participants. This response rate, and the results, are regarded as acceptable for the nature of the study.

Nine professionals associated with the data centre and digital technology sectors participated in semi-structured interviews, with 10 open questions, which lasted between 30 and $60 \mathrm{~min}$. All interviews were conducted online using video/audio software and recorded; every recording was transcribed, then analysed, using specialist software, which enabled identification of particular themes and sub-themes; the results were also crossreferenced to identify trends in expertise, attitudes, and behaviours and to assess the success and impact of the CEDaCI project model and methods to date.

All nine participants hold senior positions within their organisations, as shown in Table 5, and include: 3 sustainability leads/managers in a refurbishing company (B), an assets disposition company (E), and a national non-profit organisation (C); a Circular Economy manager for a corporate IT producer (A); an associate director for climate, environment, and sustainability in a digital technology trade association (I); a vice president of a foundation for open source hardware and data centre design (G); an ambassador for a non-profit global ICT producer (D); expert in electrical and electronics materials (F); and a technical director of a data centre consultancy $(\mathrm{H})$.

Table 5. Participants in CEDaCI Qualitative study -roles and employment.

\begin{tabular}{|c|c|c|}
\hline Identifier & Participant's Role & Participant's Role \\
\hline A & Corporate IT producer & Circular Economy manager \\
\hline $\mathrm{B}$ & Refurbishment & Sustainability manager/lead \\
\hline $\mathrm{C}$ & National non-profit organisation (digital section) & Sustainability manager/lead \\
\hline $\mathrm{D}$ & $\begin{array}{l}\text { Non-profit global ICT producer (open source hardware and } \\
\text { data centre design) }\end{array}$ & Ambassador \\
\hline $\mathrm{E}$ & Assets deposition & Sustainability manager/lead \\
\hline $\mathrm{F}$ & University & Expert in electrical and electronics materials \\
\hline G & $\begin{array}{l}\text { Non-profit global ICT producer (open source hardware and } \\
\text { data centre design) }\end{array}$ & Vice president \\
\hline $\mathrm{H}$ & Data centre consultancy & Technical director \\
\hline I & Digital technology trade association & $\begin{array}{c}\text { Associate director for climate, environment } \\
\text { and sustainability }\end{array}$ \\
\hline
\end{tabular}

\subsubsection{General Contextual Questions, Responses and Evaluation}

An overview of the responses to the general and individual questions posed is presented in Table 6 below; a more detailed review and analysis is also presented as follows: the first three questions were designed to confirm the participants' knowledge and experience in order to validate their responses to the specific questions about CEDaCI. 
Table 6. Overview of responses to semi-structured interview questions.

\begin{tabular}{|c|c|c|c|c|c|c|c|c|c|}
\hline Participants & $\mathbf{A}$ & B & $\mathrm{C}$ & D & E & F & G & $\mathbf{H}$ & I \\
\hline $\begin{array}{c}\text { Subject knowledge } \\
\text { circularity } \\
\text { efficiency } \\
\text { energy efficiency } \\
\text { materials efficiency } \\
\text { economic } \\
\text { environment } \\
\text { social } \\
\text { conflict minerals } \\
\text { data security concerns }\end{array}$ & $\mathrm{x}$ & $x$ & $\begin{array}{l}x \\
x\end{array}$ & & $x$ & & $\mathrm{x}$ & $x$ & $\begin{array}{l}x \\
x \\
x \\
x\end{array}$ \\
\hline $\begin{array}{l}\text { Sustainability within company } \\
\text { energy efficiency-now } \\
\text { economic factors-now } \\
\text { environmental factors-now } \\
\text { social factors- now } \\
\text { good practice in the future } \\
\text { IT energy savings-necessary } \\
\text { cycling-client visits etc. } \\
\text { reduce impact of travel and transport } \\
\text { sustainable practice in-house } \\
\text { philanthropic activity }\end{array}$ & $x$ & $\begin{array}{l}x \\
x \\
x \\
x\end{array}$ & $\begin{array}{l}x \\
x \\
x \\
x\end{array}$ & $\begin{array}{l}x \\
x \\
x \\
x\end{array}$ & $\begin{array}{l}x \\
x \\
x \\
x\end{array}$ & $\begin{array}{l}x \\
x \\
x \\
x \\
x\end{array}$ & $\begin{array}{l}x \\
x \\
x \\
x\end{array}$ & $\begin{array}{l}x \\
x \\
x \\
x\end{array}$ & $\begin{array}{l}x \\
x \\
x \\
x\end{array}$ \\
\hline $\begin{array}{l}\text { Project vision and change } \\
\text { positive impact of CEDaCI }\end{array}$ & $\mathrm{x}$ & $x$ & $x$ & $x$ & $\mathrm{x}$ & $x$ & $\mathrm{x}$ & & $x$ \\
\hline $\begin{array}{l}\text { Awareness raising, contribution to developing CE and initiating change } \\
\text { positive impact on Data Centre Industry }\end{array}$ & & $x$ & $\mathrm{x}$ & $x$ & $\mathrm{x}$ & $x$ & $\mathrm{x}$ & & \\
\hline $\begin{array}{c}\text { Impact of CEDaCI on participants and employers } \\
\text { beneficial support-now } \\
\text { brings specialist knowledge to company } \\
\text { beneficial support-future }\end{array}$ & $\mathrm{x}$ & $\begin{array}{l}x \\
x \\
x\end{array}$ & $\begin{array}{l}x \\
x \\
x\end{array}$ & $\mathrm{x}$ & $\mathrm{x}$ & $\mathrm{x}$ & $\mathrm{x}$ & $x$ & $x$ \\
\hline $\begin{array}{l}\text { Value of stakeholder engagement } \\
\text { new to CCWs and WGs } \\
\text { prior experience of CCWs and WGs } \\
\text { cross-sectoral activities are beneficial }\end{array}$ & $x$ & $\begin{array}{l}x \\
x\end{array}$ & $x$ & $\mathrm{x}$ & $\mathrm{x}$ & $\begin{array}{l}x \\
x \\
x\end{array}$ & $x$ & $\begin{array}{l}x \\
x\end{array}$ & $\begin{array}{l}x \\
x\end{array}$ \\
\hline $\begin{array}{c}\text { Future activities } \\
\text { economics of CE } \\
\text { ethical procurement } \\
\text { broadening scope of LCAs etc. }\end{array}$ & & $x$ & $\begin{array}{l}x \\
x\end{array}$ & $\mathrm{x}$ & & $x$ & $x$ & $x$ & \\
\hline
\end{tabular}

Participants were first asked for their definition of data centre sustainability: the most common subject was circularity, which was mentioned by (B), (C), (G), (H), and (I) who all had a good understanding of the principles of the circular economy, that the embodied impact of products is as important as that of operational energy and the need for a holistic approach to the challenge. (A) — the Circular Economy lead—did not mention circularity as such but alluded to it in points about the complexity of data centre sustainability, whole product life cycles, removal of redundant equipment, space used, and operational efficiency; both (A) and (C) commented on efficiency, and it is worth noting that both work for very large (global and national) organisations.

Economic, environmental, and social factors were each mentioned by 2 participants. (B) and (I) mentioned economics, and (E) and (I) mentioned the environment; all of their comments were linked to operational energy consumption, associated impacts, and use of renewables rather than physical resources, which was a little surprising considering the participants' comments regarding the circular economy. (C) and (I) mentioned social factors, although their emphasis was different, and while (C) referred to concerns about data security, 
(I) referred to conflict minerals, which is keeping with their respective roles-(C) within a national operator that relies on DCI services and (I) a technology advisory organisation; in fact (I)'s entire response to data centre sustainability was the broadest, and all subjects, other than efficiency were specifically mentioned, which is also in keeping with role.

The second and third questions were about the participants' organisations (employers), what they are, and what they could be doing better in relation to sustainability. Economic, energy efficiency, social, and environmental factors were identified in response to question 2, and all participants other than (A) mentioned these in relation to current activities within their organisations, although (A) did talk about potential and future improvements. The subjects and responses were significantly interlinked, and participants referred to in-house and external practices (with clients and customers). All participants cited examples of good practice, but they varied according to the focus and size of the organisation and local political factors. For example, $(\mathrm{H})$ works for a small consultancy, and all employees work remotely at home, or on site, with clients; although the employees are encouraged to cycle to sites, energy efficiency is dependent on personal habits at home. Conversely, (C) works for a huge national organisation and has driven good practice to make significant energy and resource savings across their IT activities. Employees of customer and client facing organisations ((B), (D), (E), (G), (H), (I)) are also driving good practice as part of their business and activities (e.g., increasing energy efficiency, extending product life, and reducing packaging and general waste to reduce environmental impact) and developing strategies, tools, products, and services to help their clients to do the same. There are also examples of philanthropy, and one refurbishment company donates unsalable, but fully functioning, products to organisations that develop IT skills in developing countries and support local charities that help people with special needs. There were several common observations, including the lack of robust recognised metrics and standards, for the secondary market and products; although several organisations are developing their own, they will not be comparable with each other, which may be confusing for customers who want to compare metrics.

Another common point relates to the increasing awareness of embodied impact and frustration at the lack of infrastructure, or policy, to guide and bring about significant change. (F) noted that, until recently, his organisation would not buy second life (refurbished) equipment because of issues around warranties; however, this is changing in response to policy change (specifically Wales' Well Being of Future Generation act), which is encouraging more circular practice, which could drive common metrics and standards. Finally, the general consensus of $(\mathrm{C}),(\mathrm{G})$, and $(\mathrm{H})$ who are influencing change in house, and with external clients, is that sustainability has to be linked to the bottom line.

Unsurprisingly, subjects raised in response to question 3 included future, growth, and targets in addition to economic, environmental, and social factors. Both (E) and (G) were confident that their business practices are as sustainable as they can be at the moment, although $(G)$ would like open-source hardware to be included in policy to increase market growth for this type of product as an alternative to being locked into single brands. This is contrary to (A), who works for a company that is seeking to increase brand loyalty by selling a service rather than equipment, one benefit of which is that the company will have control over the entire product life cycle from cradle to cradle. $(\mathrm{B})$ and $(\mathrm{H})$ mentioned that they could reduce the impact of travel and transport of goods, while (C) mentioned that the sustainability programme now includes resilience, so it can cope with emerging and future challenges, such as COVID-19, pandemics, and climate shocks. Finally, (I) commented that the organisation is based in rented premises, and they don't control waste and recycling at present, but they are measuring their current activities, so they can make their business activities more sustainable, and this includes signing up to the Race to Zero (carbon reduction) initiative. In general, all participants simultaneously recognised current good practice in their organisation and the need to improve.

This investigation and analysis of participants' current knowledge and workplace activities, practice, and attitudes provided extremely important insights into their business 
practice, role, and trends across the sector. It also confirms that their opinions about, and responses to, the CEDaCI project are based on high level of knowledge and experience. The subsequent questions related their reaction to, and perception of, the CEDaCI project as a whole and highlighted the value of stakeholder engagement.

\subsubsection{Response to and Evaluation of the CEDaCI Project Individual Questions}

Question 4, the first in the section, relates to the project vision and asked whether $\mathrm{CEDaCI}$ is accelerating development of a sectoral Circular Economy: the response was almost unanimously positive and even the participant who responded negatively $(\mathrm{H})$ qualified their response and commented that it was impossible "because it is such a huge task but the project is raising awareness of the Circular Economy and is making decision makers think." All other responses were very positive: and 4 further participants ((B), (D), (F), and (G)) commented that the project is raising awareness and "has opened conversation that wasn't there before and people didn't bother thinking about before' "despite limited resources."

Awareness raising is the first step in the development of the Circular Economy; second steps involve supporting and empowering businesses and organisations to make change. The participants were again very encouraging and commented that "It is the first (project) to investigate the challenge analytically" and "the potential is huge" (B); "the project is also bridging the gap between theory and practical guidance" $(\mathrm{C})$ and the output (specifically the digital Circular Data Centre Compass (CDCC)) "is immensely valuable" (F) and will "support public and private organisations to make informed decisions about procurement and practice" (E). Similarly, if we "make those (tools) available to organisations and they are able to use them easily and adopt them, you've solved a huge issue that most places don't have the time to look at. If you simplify the process for them, it removes huge barriers" (F).

Question 5 was designed to find out whether CEDaCI is supporting the DCI in general; all participants responded very positively, highlighted subjects were (again) awareness, circularity, green procurement, the public sector, market visibility, and the CDCC digital tool. The responses acknowledged the wider benefits and impact of CEDaCI; for example, "The tools that you have provided will be hugely helpful for operators who currently still are very energy and carbon focused and they are not thinking about the embedded carbon in the assets that they use" (I). The link between economics and sustainability was repeated and "Anybody who adopts your tools and uses them properly should make more money. This means that they can save the planet and create social value and sustainable options for the future" (F). The project output has the potential to influence change "provided that important buyers like the government and others start requesting this information and demanding action it will drive the market accordingly" (C). This could be realised because one participant is already referencing CEDaCI to government bodies, such as DEFRA, who are developing a Cloud Sustainability Standard and another wants to "showcase the CDCC to the Cross-Government Technology Group to get feedback and as a game changer for their thinking" (C).

Questions 6 and 7 were designed to gather more specific feedback about the impact of CEDaCI on the participants and their organisations now and in the future; some of the subjects identified were the same as those raised by other questions (business, future, and growth) but they also included planning and support. Again, all participants responded positively and commented that support for current business practice was highly beneficial; for example, "Those involved in sustainability impact roles can use this information to make their case in their organisations for sustainable choices to be made" (D). Examples of specific projectpartnership tasks include checking other LCAs and carbon assessments in the public domain and creating new LCAs of open source hardware; participants (B) and (C) agreed that the $\mathrm{CEDaCI}$ team bring different specialist knowledge to their organisations and that external analysis and reports increase objectivity and credibility ("The findings ... . published by someone like you will be invaluable" $(\mathrm{G})$ ). They also expect that project output will continue to support them in the future, as more output like the CDCC and Pilot projects are completed. Several participants also made suggestions for future work and collaboration after the 
project: for example, "You have the data with the Compass and when we talk to the big systems integrator about the data centre contract, I think CEDaCI could help support us" (E). Similarly, "It's likely that sustainability principle will be added to our code of practice so you could look at how to mesh your thinking and tool into how the public sector operates" (C).

Like question 4 , question 8 was designed to learn whether the project process and output was fulfilling a key aim: as explained above, the DCI is fragmented and silo working is endemic across subsectors. Development of a Circular Economy requires a holistic approach and input from representatives from all life cycle stages across an entire industry. $\mathrm{CEDaCI}$ is seeking to do this, and although the (internal) team recognises that there is some progress and shortfalls, external feedback from participants is essential to confirm or negate this perception. Consequently, participants were asked whether the mix and composition of partners, Working Group, and Co-creation Workshop members is right. The question encouraged comments around the environment, suppliers, manufacturers, and users from $7 / 9$ participants. The feedback was mixed, but this was expected because, despite major efforts to recruit DC operators, most said they were too busy to join the activities although consultants with prior experience of running data centres were a good substitute. A typical comment was "There was a great mix of people. There could be more users involved in the development process" (I). Similarly, the team were unable to engage manufacturers in the project regularly; they visited a global IT producer's site in Scotland, but their production plant, like those of other manufacturers, is outside the UK so the visit was to a "technology renewal" reuse and recycling centre. Again, low engagement was due to high volume of work and other typical comments were "End users and manufacturers lacked representation, but that is understandable as many are distributed globally" $(\mathrm{H})$. The participants believe that there is potential to engage with more users and manufacturers when the outputs-and especially the CDCC tool—are complete.

Question 9 related to perception of the Working Groups and Co-creation Workshops and the value of stakeholder engagement: 8/9 participants responded when asked whether they had taken part in similar events prior to the CEDaCI events and 50\% (A), (C), (D), (F) said no, or not in the way that the CEDaCI activities were run, and the other $50 \%(B),(G)$, (H), (I) said yes but made comments like "I've learnt more from CEDaCI than from anywhere else apart from our own research" (B). When asked about the benefits of the cross-sectoral WGs and CCWs to the CEDaCI project, and to them as individuals, all 8 participants responded very positively and the general consensus was that the events were very successful in initiating different ways of thinking about problems. For example, "The key thing is a change of consciousness. You are getting people to think about new ideas" (D). The format also encouraged open and objective conversations, which participants really appreciated: "To get all those people involved was a major challenge, discussing openly problems and solutions. They are able to freely talk about ideas and mutual benefit" (F); "it helps to ensure that you can take account of scoping issues by bringing together the supply chain and actors that might not normally come together. It's good to hear different perspectives and have a balanced view, without it being influenced by vested interests" (B). Participants also valued the interdisciplinary composition of the meetings and (I) "found it interesting to hear other people's perceptions and views that I would not have had access to otherwise" while (G) said "each one of the meetings felt useful" and "the biggest benefit is meeting other people with other perspectives. The community aspect is one of the benefits of working groups".

In the last question (10), participants were asked for suggestions about future activities or events: the response was encouraging and indicated that there is scope for future work to extend the impact of CEDaCI by organising a "meeting or event where you discuss your approach to developing those tools and how you can help others to build similar things or transfer to different industries" (F). Ethical procurement issues (C) and understanding "more about the chemical processes that are used to extract elements" $(\mathrm{H})$ and (in response to HM Treasury Business Case) (C) said that factoring "sustainability into business decisions and working that through to monetised values ... would be really useful"; broadening research and modelling to include all types of current and emerging DC equipment (D), were also highlighted as 
subjects for further investigation. The most significant suggestion that was made by several participants, concerning wider dissemination of project output to inform and educate the DCI, other industries, and the public: for example, (I) suggested a briefing event or blog for members of the technology trade association, $(\mathrm{H})$ felt that publicising information about the overall manufacturing process would generate interest in the industry, $(G)$ will be happy to do a joint webinar for their business community so they can see the end results once the tool is released, and (B) said "you can reach a lot wider audience and you can educate them about what's in the technology and from a sustainability point of view, it has the benefit of educating people about data and ICT as well."

\section{Aggregated Data and Trends}

The key themes identified in the transcripts are shown in Figure 5 below, which also shows frequency. Aggregation and analysis of qualitative data, generated by responses to all 10 questions, showed that of the 17 themes identified in the transcripts the most common was the environment (identified 15 times), followed by circular/circularity and economic (8); efficiency/energy efficiency (7), social and support (6), awareness, future, manufacture, and public sector (4), growth and market visibility (3), business, green procurement, target, and users (2) and tool (1). Considering the interests (i.e., all bar one have engaged with the CEDaCI project and take part in WGs and CCWs), expertise and roles within the organisations ( 5 are directly linked to sustainability, 3 are linked to overall efficiency and 1, sustainability-linked research) these results are not surprising; similarly, alignment of the themes with the individual participants reflected the type of organisation with which they work: for example the (A) (who works for a corporate global IT producer) focussed on efficiency, growth, manufacture, and targets; (B) and (E), who work for SMEs specialising in refurbishment/second life products and recycling, focused on the three tenets of sustainability, education, and circularity, as did (C), who also commented on the public sector and works for a national non-profit organisation; (D) and (G) work for a non-profit global open-source IT provider, and both referred to sustainability-linked criteria and the future growth; (F) (who works in a university) focused on the environment and economics as did (H), the technical consultant who also spoke of manufacture and business. Finally, (I) who works for an advisory body, mentioned the broadest range of themes, including sustainability and circularity, business, manufacture, planning, public sector, the future, and targets.

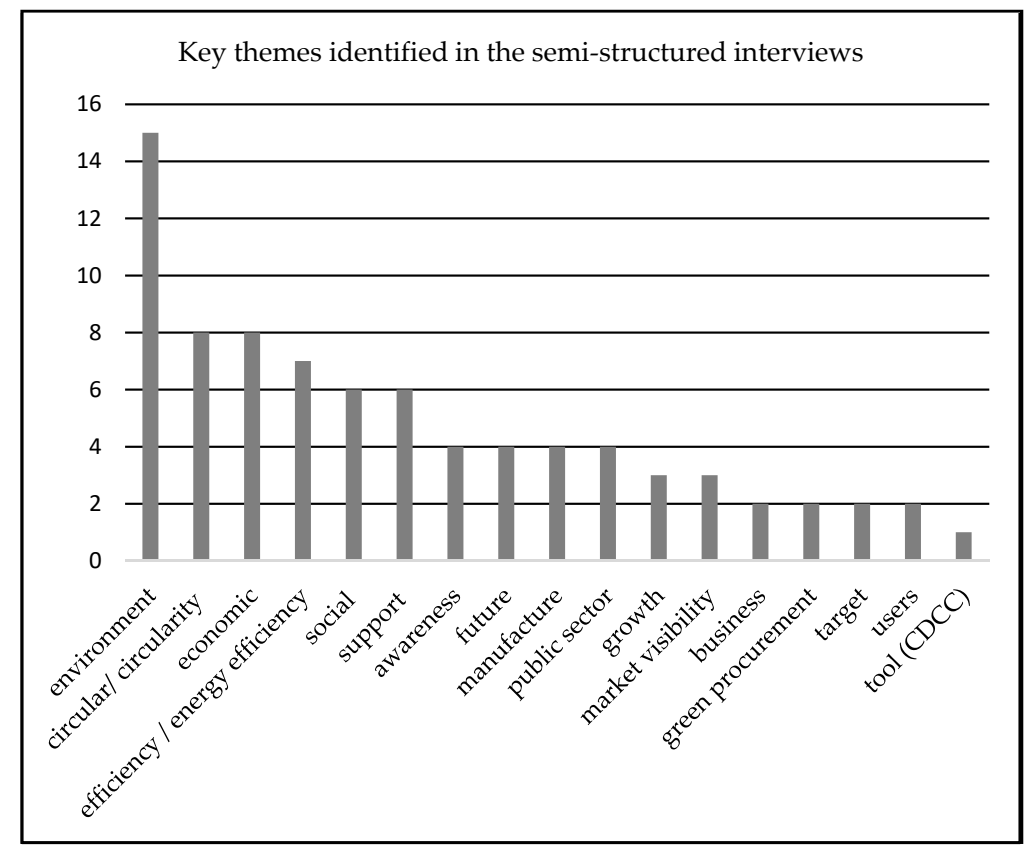

Figure 5.17 Key themes identified in the semi-structured interviews by frequency. 


\section{Discussion}

This paper began with a brief history of computing and the data centre industry, outlining established thought process and practice in the general engineering profession and data centre industry. This review was necessary in order to contextualise the scale and nature of the current and future challenges facing the sector unless there is a significant change from a linear to circular economy. The paper then describes two methods (Design Thinking and the Double Diamond Framework for Innovation), which underpinned CEDaCI, a unique project that was set up to kick start the Circular Economy for the Data Centre Industry. People and stakeholder engagement are central and critical to the design methods; however, the DCI is very fragmented and silo working is the established practice in the various sub-sectors so there was a risk that the project would be compromised, or fail to deliver, because of lack of engagement. The project team used various strategies to engage stakeholders; this has proved successful so far, and the CEDaCI team has built a Network with 100 members. All Working Groups meetings and Co-creation Workshops are also well-attended, and participants appear to fully engage with the project team and each other throughout.

In order to assess the impact of the project, the level of stakeholder engagement and the success of the design methods, quantitative and qualitative data were collected and analysed via an on-line survey and semi structured interviews. The overall response from this research indicates that the project is very well received and is fulfilling aims so far; the enormous scope of the project means that creating a sectoral circular economy in three and a half years is unrealistic but the project is raising awareness across the sector and demonstrating that a $\mathrm{CE}$ is possible. For example, participant (D) volunteered that " $C E D a C I$ has created an awareness and an interest to look into the topic of the circular economy. That's a huge success. That will create a big change on the market".

The participants' response to the WG meetings and CCWs has exceeded expectations; the aim of these events to was to bring together actors from across the DCI to enable whole systems approach, to address the challenge of a sectoral Circular Economy, by encouraging knowledge transfer and exchange, and the following comments from participants indicate that this objective is being realised: for example, (F) commented that "You must be achieving (the Circular Economy) to some extent because there has been awareness raising. You have brought together stakeholders from around the value chain. They have knowledge that no others do." And "I've met some interesting people that I've been able to bounce ideas off of. Some of the experts bring insight and knowledge that I couldn't get from the papers" and (G) said that "the biggest benefit is meeting other people with other perspectives. The community aspect is one of the benefits of working groups". Stakeholder engagement is proving mutually beneficial and the CEDaCI team are continually learning from the industry partners; what is learned is feeding into the Pilot projects, and other output, to ensure that it both meets DCI requirements and initiates change towards a circular economy.

Although the feedback from the two research exercises is all very positive, it must be remembered that the research has limitations: the participants are already committed to sustainability and sustainable development, and they all work for organisations that are either promoting and/or practicing it. A bigger challenge is engaging and educating stakeholders who are not interested, are still totally focussed on energy efficiency (rather than that and physical resources), or believe that any products that are sent for recycling are actually recycled rather than being stockpiled, sent to a landfill, or that second life products cannot possibly meet their requirements.

These stakeholders may be forced to change practice in order to conform to any new and future legislation, although the $\mathrm{CEDaCI}$ project will publicise incentives such as the CDCC tool, models, and case studies to illustrate the economic, and other, benefits of adopting circular practices.

Despite these short comings, the research shows that project is leading change, which validates the use of design methods; the project is also an exemplar, and the meth- 
ods and underlying structure can also be transferred to other sectors to support their transformation to circularity.

Supplementary Materials: The following are available online at https:/ /www.mdpi.com/article/10 $.3390 /$ su13116319/s1, The supplementary materials comprise questions for qualitative and quantitative data collection via the on-line survey and the semi-structured interviews.

Author Contributions: Conceptualization, D.A., N.A., J.C. and K.B.; methodology, D.A, N.A., J.C. and K.B.; software, E.J.N.; validation, D.A.; E.J.N.; formal analysis, D.A. and E.J.N.; investigation, D.A., N.A., J.C. and K.B.; resources, E.J.N.; data curation, E.J.N.; writing-original draft preparation, D.A.; writing - review and editing, D.A. and E.J.N.; funding acquisition, D.A. and N.A. All authors have read and agreed to the published version of the manuscript.

Funding: This research was funded by ERDF/INTERREG NORTH WEST EUROPE, grant number 787.

Institutional Review Board Statement: The study was conducted according to the guidelines of the Declaration of Helsinki, and approved by the Institutional Ethics Committee of LONDON SOUTH BANK UNIVERSITY (protocol code SoE28012021; approval confirmed by Chair of Ethics via email on 28 January 2021).

Informed Consent Statement: Informed consent was obtained from all subjects involved in the study.

Data Availability Statement: Anonymised data can be obtained by contacting the lead author.

Conflicts of Interest: The authors declare no conflict of interest.

\section{References}

1. Statista. Number of Data Centers Worldwide in 2015, 2017, and 2021. Available online: https://www.statista.com/statistics/5004 58/worldwide-datacenter-and-it-sites (accessed on 11 January 2021).

2. Masanet, E.; Shehabi, A.; Lei, N.; Smith, S.; Koomey, J. Recalibrating global data center energy-use estimates. Science 2020, 367, 984-986. [CrossRef] [PubMed]

3. Pearce, F. Energy Hogs: Can World's Huge Data Centers Be Made More Efficient? Available online: https://e360.yale.edu/ features/energy-hogs-can-huge-data-centers-be-made-more-efficient (accessed on 3 April 2018).

4. Data Economy. Data Centers 'Going Green' To Reduce A Carbon Footprint Larger Than the Airline Retrieved from Industry. Available online: https:/ / data-economy.com/data-centers-going-green-to-reduce-a-carbon-footprint-larger-than-the-airline-industry / (accessed on 1 June 2017).

5. Hootsuite. Digital 2020 October Global Statshot Report. Available online: https://www.hootsuite.com/resources/blog/digital-2020 -report (accessed on 15 January 2021).

6. IEA. Data Centres and Data Transmission Networks, Tracking Report. Available online: https://www.iea.org/reports/datacentres-and-data-transmission-networks (accessed on 15 January 2021).

7. Freeth, T.; Higgon, D.; Dacanalis, A.; Mac Donald, L.; Georgakopoulou, M.; Wojcik, A. A Model of the Cosmos in the ancient Greek Antikythera Mechanism. Sci. Rep. 2021, 11, 1-15. [CrossRef] [PubMed]

8. Charman-Anderson, S. Ada Lovelace: Victorian computing visionary. Available online: https://findingada.com/shop/a-passionfor-science-stories-of-discovery-and-invention/ada-lovelace-victorian-computing-visionary/ (accessed on 20 January 2021).

9. Turing, A.M. On Computable Numbers, with an Application to the Entscheidungsproblem. In Proceedings of the London Mathematical Society, London, UK, 1 December 1937; Volume s2-42, pp. 230-265. [CrossRef]

10. Atkinson, P. Computer; Reaktion Books: London, UK, 2011.

11. Atkinson, P. A Design History of Computer Vapourware; Bloomsbury Academic: London, UK, 2013.

12. Andrews, D.; Whitehead, B. Data Centres in 2030: Comparative case studies that illustrate the potential of Design for the Circular Economy as an enabler of Sustainability. In Proceedings of the Sustainable Innovation 2019 22nd International Conference Road to 2030: Sustainability, Business Models, Innovation and Design, Epsom, UK, 4-5 March 2019; University for the Creative Arts Business School: Epsom, UK, 2019.

13. Flucker, S.; Whitehead, B.; Tozer, R.; Andrews, D. Energy and Water Environmental Trade-Offs of Data Center Cooling Technologies. In Proceedings of the ASHRAE Winter Conference, Las Vegas, NV, USA, 20-24 January 2017.

14. Tozer, R.; Flucker, S.; Whitehead, B.; Andrews, D.; Summers, J. Data Center Sustainability Indices. In Proceedings of the ASHRAE Winter Conference, Chicago, IL, USA, 20-24 January 2018.

15. Myers, K. Data Center Knowledge A Data Center That Guzzles Water Isn't Sustainable. Available online: https://www. datacenterknowledge.com/industry-perspectives/data-center-guzzles-water-isn-t-sustainable (accessed on 13 April 2020).

16. Forti, V.; Baldé, C.P.; Kuehr, R.; Bel, G. The Global e-Waste Monitor 2020: Quantities, Flows and the Circular Economy Potential; United Nations University: Bonn, Germany; United Nations Institute for Training and Research: Geneva, Switzerland; International Telecommunication Union: Geneva, Switzerland; International Solid Waste Association: Rotterdam, The Netherlands, 2020. 
17. European Commission. Report on Critical Raw Materials in the Circular Economy. Available online: http:/ / publications.europa. eu/resource/cellar/d1be1b43-e18f-11e8-b690-01aa75ed71a1.0001.01/DOC_1 (accessed on 15 December 2018).

18. European Commission. Critical Raw Materials for Strategic Technologies and Sectors in the EU-A Foresight Study. Available online: https: / / rmis.jrc.ec.europa.eu/?page=crm-list-2020-e294f6 (accessed on 20 October 2020).

19. Mining.com. The Chinese Scramble to Mine Africa. Available online: https://www.mining.com/feature-chinas-scramble-forafrica/ (accessed on 15 December 2015).

20. Baruzzi, S.; Shera, D.; Associates. China Tightens Control Over Management of Rare Earths China Briefing China's Export Control Law. Available online: https://www.china-briefing.com/news/chinas-export-control-law-explainer-china-briefing-news/ (accessed on 9 November 2020).

21. Bento, F.; Tagliabue, M.; Lorenzo, F. Organizational Silos: A Scoping Review Informed by a Behavioral Perspective on Systems and Networks. Available online: www.forbes.com/sites/brentgleeson/2013/10/02/the-silo-mentality-how-to-break-downthebarriers / ?sh=c62fe0d8c7e920 (accessed on 2 October 2013).

22. Brown, T. Design Thinking: Thinking Like a Designer Can Transform the Way You Develop Products, Services, Processes-and Even Strategy. Harvard Business Review. Available online: https://hbr.org/2008/06/design-thinking (accessed on 1 June 2014).

23. Brown, T. Change by Design: How Design Thinking Transforms Organizations and Inspires Innovation, 1st ed.; HarperCollins: Glasgow, Scotland, 2009.

24. Norman, D.; Nielsen, J. Design Thinking 101. Available online: https://www.nngroup.com/articles/design-thinking/ (accessed on 31 July 2016).

25. Siang, T.Y. Interaction Design Foundation. Available online: https://www.interaction-design.org/literature/topics/designthinking (accessed on 20 January 2021).

26. Liedtka, J. Why Design Thinking Works It addresses the biases and behaviors that hamper innovation. Harvard Business Review, The Magazine, September-October 2018. Available online: https://hbr.org/2018/09/why-design-thinking-works (accessed on 20 January 2021).

27. Møller Institute. Design Thinking with Purpose. Available online: https://www.mollerinstitute.com/open-programmes/designthinking-with-purpose/ (accessed on 20 January 2021).

28. MIT. Management Sloan Executive Education. Available online: https:/ / executive-ed.mit.edu/mastering-design-thinking?utm_source= Google\&utm_medium =c\&utm_term=\%2Bdesign\%20\%2Bthinking\&utm_location=9050373\&utm_campaign=B365D_TC2_GG_SE_MDT_ Core_UKAUS\&utm_content=Design_Thinking\&gclid=CjwKCAjw9MuCBhBUEiwAbDZ-7sjsNzbHCbgwZKdCtmZvn_SvTWTUcJCak_ ySSdumCmgH87kcRmqhthoCQ6gQAvD_BwE (accessed on 20 January 2021).

29. Ball, J. Design Council from Humble Beginnings to A Corner Stone of Design Language. Available online: https: / / www.designcouncil. org.uk/news-opinion/double-diamond-universally-accepted-depiction-design-process (accessed on 10 October 2019).

30. Design Council. What is the Framework for Innovation? Design Council's Evolved Double Diamond. Available online: https: / / www.designcouncil.org.uk/news-opinion/what-framework-innovation-design-councils-evolved-double-diamond (accessed on 18 March 2015).

31. Gardner, J.; Dowd, A.-M.; Mason, C.; Ashworth, P. A Framework for Stakeholder Engagement on Climate Adaptation. CSIRO Climate Adaptation Flagship Working Paper No.3. Available online: https://research.csiro.au/climate/wp-content/uploads / sites/54/2016/03/3_CAF_WorkingPaper03_pdf-Standard.pdf (accessed on 20 January 2021).

32. Kahn, W.A. Psychological conditions of personal engagement and disengagement at work. Acad. Manag. J. 1990, 33, 692-724. [CrossRef]

33. Dijkmans, C.; Kerkhof, P.; Beukeboom, C.J. A Stage to engage: Social media use and corporate reputation. Tour. Manag. 2015, 47, 58-67. [CrossRef]

34. Brodie, J.; Ilic, A.; Juric, B.; Hollebeek, L. Consumer engagement in a virtual brand community: An exploratory analysis. J. Bus. Res. 2013, 66, 105-111. [CrossRef]

35. Barnett, M.I. Why stakeholders ignore firm misconduct: A cognitive view. J. Manag. 2014, 40, 676-702. [CrossRef]

36. Pera, N.; Occhiocupo, J. Clarke Motives and resources for value co-creation in a multi-stakeholder ecosystem: A managerial perspective. J. Bus. Res. 2016, 69, 4033-4041. [CrossRef] 